\title{
Por uma estratégia equitativa de vacinação da população privada de liberdade contra a COVID-19
}

\author{
For an equitable COVID-19 vaccination strategy \\ for the population deprived of liberty
}

\author{
Por una estrategia de vacunación equitativa \\ contra COVID-19 para la población privada \\ de libertad
}

Luciana Simas 1

Bernard Larouze 1

Vilma Diuana 1

Alexandra Sánchez 1

doi: 10.1590/0102-311X00068221

As pessoas privadas de liberdade (PPL) têm risco elevado de infecção pelo SARS-CoV-2, especialmente em países de baixa e média renda como o Brasil, onde mais de 700 mil PPL vivem, na maioria, em celas coletivas, insalubres, pouco ventiladas, superlotadas 1 e, não raro, com acesso limitado a água. Essas condições desumanas 2 não permitem respeitar as principais medidas preconizadas para prevenção da pandemia, quais sejam, distanciamento social e medidas de higiene individuais e coletivas 3 . As máscaras faciais disponibilizadas em algumas prisões são utilizadas, na maioria das vezes, só para deslocamentos externos e raramente no interior das celas, onde a situação de aglomeração é permanente. Como medidas de contenção da transmissão, foram interrompidas visitas, transferências entre unidades prisionais e atividades coletivas em escolas e oficinas e mesmo o banho de sol, que se tornou mais raro. Por outro lado, foram pouco aplicadas medidas desencarceradoras, recomendadas pelo Conselho Nacional de Justiça $(\mathrm{CNJ}){ }^{4}$, para reduzir a superlotação nas prisões por meio da liberdade provisória ou definitiva de PPL em final de cumprimento da pena ou em regime semiaberto, ou ainda prisão domiciliar para aqueles com maior risco de evolução grave ou fatal, sejam presos com comorbidades (grupos de risco), sejam presos idosos (1,26\% [9.489] das PPL no Brasil tem mais de 60 anos) 5. Em poucas locais, as PPL idosas foram isoladas em algumas prisões, para se beneficiarem de um acompanhamento médico reforçado.

Os dados oficiais sobre infecções e óbitos publicados pelo Departamento Penitenciário Nacional (DEPEN) do Ministério da Justiça 6, a partir de informações fornecidas pelas administrações estaduais, não permitem dimensionar a real situação epidemiológica da COVID-19 nas prisões, devido ao extremamente limitado acesso das PPL ao teste RT-PCR e ao fato de serem incluídos nesse sistema unicamente casos laboratorialmente confirmados. A isso soma-se a suspensão da realização, em decorrência da pandemia, de necrópsias de pessoas presas e a impossibilidade de detectar os óbitos por COVID-19 ou por síndrome respiratória aguda grave (SRAG) considerados como suspeitos de COVID-19, ocorridos durante o encarceramento, por meio do Sistema de Informações sobre Mortalidade (SIM), que não permite identificar a origem prisional dos falecidos. Recente levantamento do CNJ assinala aumento de 190\% nas mortes por COVID-19 nas prisões nos primeiros 67 dias de 2021 em relação aos últimos 70 dias de 2020 ( $\mathrm{n}=20$ óbitos vs. 58) 7. Além disso, por meio dos dados do DEPEN, é possível observar ao nível nacional, entre 2019 e 2020, um aumento da taxa global de óbitos em PPL > 60 anos da ordem de 25\%, sugerindo impacto significativo da COVID-19 na mortalidade entre os idosos encarcerados.
1 Escola Nacional de Saúde Pública Sergio Arouca, Fundação Oswaldo Cruz, Rio de Janeiro, Brasil.

\section{Correspondência}

A. Sánchez

Escola Nacional de Saúde Pública Sergio Arouca, Fundação Oswaldo Cruz. Rua Leopoldo Bulhões 1480, oo andar, Rio de Janeiro, $R J$ 21041-210, Brasil. alexandra.sanchez@ensp. fiocruz.br 
Dada a impossibilidade de aplicação efetiva às PPL de medidas de prevenção fundamentais, é possível inferir que a pandemia nas prisões não poderá ser contida, mesmo que de maneira parcial, sem vacinação. Como são cidadãs e cidadãos brasileiros, as PPL, vivendo sob a responsabilidade do Estado, devem se beneficiar das mesmas estratégias de prevenção, especialmente o acesso às vacinas, tal como a população livre. Como disse a ministra inglesa Lucy Frazer 8: "As pessoas privadas de liberdade serão vacinadas, assim como a comunidade, como devem ser”. Assim, as lógicas sanitárias e éticas deveriam prevalecer e, por seu alto risco de infecção, essa população deve ser incluída entre os grupos prioritários para vacinação contra a COVID-199.

Mas a lógica política, especialmente no contexto mundial de disponibilidade limitada de vacinas, parece, em vários lugares, superar os pressupostos éticos e sanitários. No estado norte-americano do Colorado, o governador Jared Polis se posicionou inicialmente no debate sobre prioridades de vacinação, alegando que: "De maneira nenhuma [a vacina contra COVID-19] irá para a população carcerária antes de vacinar as pessoas que não cometeram nenhum crime. Isso é óbvio" ${ }^{8}$. Essa fala emblemática traduz uma visão de que as PPL "não mereceriam" ser vacinadas no mesmo nível que a população livre, chancelando, por meio da palavra do governante, uma imagem discriminatória sobre as PPL, desconsiderando a responsabilidade estatal. Foi necessário um amplo debate sobre o assunto para que as PPL desse estado fossem incluídas entre os grupos prioritários. Por outro lado, não foi contestada a prioridade dada à vacinação dos funcionários do sistema prisional, plenamente justificada, mas que traduz uma percepção discriminatória do risco em relação às PPL, com as quais compartilham o mesmo ambiente atrás dos muros das prisões.

No Brasil, no início das discussões técnicas acerca da elaboração do Plano Nacional de Operacionalização da Vacinação contra a COVID-19 (PNOV-COVID-19), as PPL integravam a fase 4 de vacinação 10, depois dos profissionais de saúde, idosos, indígenas e pacientes com comorbidades. Receberiam vacinas juntamente com professores, forças de segurança e salvamento, bem como funcionários do sistema prisional, considerando-se critérios epidemiológicos referendados por diversos órgãos técnicos consultados pelo Ministério da Saúde. Todavia, o Governo Federal prestou informações ao Supremo Tribunal Federal (STF), no processo que discute a distribuição de vacinas contra o coronavírus para toda a população (ADPF no 754/DF), apresentando uma versão do Plano 11, sem incluir a população prisional nos grupos prioritários. Após muita reação por parte de diferentes setores, a Secretaria de Vigilância em Saúde do Ministério da Saúde revisou o Plano e encaminhou nova versão ao STF 12, indicando a população prisional como grupo prioritário pela elevada vulnerabilidade social, considerando-se que as condições do aprisionamento elevam a possibilidade de contaminação. Nesse documento, o Governo Federal determina que o planejamento e a operacionalização da vacinação nos estabelecimentos penais sejam articulados com as Secretarias Estaduais e Municipais de Saúde e Secretarias Estaduais de Justiça (Secretarias Estaduais de Segurança Pública ou correlatos), de acordo com a Política Nacional de Atenção Integral à Saúde das PPL no Sistema Prisional (PNAISP).

Um ponto extremamente importante é que o PNOV-COVID-19, no que se refere à população privada de liberdade, desconsidera a existência, nessa população, de integrantes dos grupos reconhecidamente de maior risco de evolução grave ou fatal, como idosos com > 60 anos e/ou portadores de comorbidades (diabetes mellitus; insuficiência renal; doenças cardiovasculares e cerebrovasculares; hipertensão arterial grave; imunodeficiência, como a determinada pela infecção pelo HIV/aids; doença pulmonar crônica, como asma; extensas lesões pulmonares consequentes de tuberculose; anemia falciforme; neoplasias, dentre outras), cuja vacinação é considerada como de elevada prioridade na população livre. Essas comorbidades são especialmente frequentes entre PPL 13, que pertencem aos estratos mais vulneráveis da população e cuja situação de saúde se agrava pelas importantes limitações do sistema de saúde prisional. De acordo com os princípios constitucionais de igualdade e universalidade do acesso à saúde, as PPL que pertencem aos grupos de risco devem ser incluídas no calendário estabelecido para a população em geral, como ocorre, por exemplo, na França e, no Brasil, no Distrito Federal 13, que recentemente iniciou a vacinação dos idosos encarcerados por faixa etária. Em particular, não há que se considerar que presos idosos encarcerados tenham menor risco de infecção pelo SARS-CoV-2 e de evolução mais branda do que idosos vivendo em asilos, abrigos ou casas de repouso, uma vez que as condições ambientais e o acesso à assistência tendem a ser piores nas prisões. Nessa mesma lógica, os funcionários do sistema prisional, sejam eles profissionais de saúde $>60$ anos, sejam profissionais de segurança com comorbidades, estão sendo e serão vacinados, de maneira assertiva, 
de acordo com o calendário previsto para sua condição individual, que prevalecerá em detrimento do seu pertencimento ao grupo de profissionais do sistema penitenciário.

Deve ser ressaltado que a COVID-19, na medida em que centraliza os recursos humanos e materiais dos já fragilizados serviços de saúde do sistema prisional, tende a reduzir a atenção para outras doenças, especialmente as crônicas e infeciosas, muito comuns na população prisional 14. Assim, além de medidas de controle básicas, a vacinação contra o SARS-CoV-2 constitui um elemento importante para melhorar a assistência à saúde global dos presos. Nesse sentido, o Conselho Nacional de Política Criminal e Penitenciária pondera que quanto maior a demora da vacinação, maiores serão os gastos com prevenção e assistência à saúde da população carcerária, evitando que esses recursos sejam disponibilizados para outras áreas que necessitam de atenção 15.

Outro aspecto a ser considerado no ambiente carcerário, embora ainda desconhecido, é a eventual emergência e o grau de circulação atual de novas variantes do SARS-CoV-2. Algumas são mais transmissíveis e - mesmo que ainda não confirmado - poderiam ser, com especial frequência, responsáveis por formas graves da doença, propiciando o surgimento de novas ondas epidêmicas intramuros.

Em uma perspectiva de garantia dos direitos humanos, as PPL devem receber tratamento com os mesmos critérios que estabelecem a hierarquização dos riscos e as prioridades aplicadas à população geral, sem razões para distingui-los, prevalecendo sua condição individual sobre o fato de, temporariamente, integrarem a população prisional. Nesse sentido, na difícil e limitada alocação das vacinas, a busca por um equilíbrio com equidade deve considerar as comorbidades, a idade e o ambiente no qual essas pessoas estão inseridas 9 .

A vacinação contra o coronavírus deve ser um instrumento de reversão de iniquidades em saúde para as pessoas que mais precisam, tal como a população carcerária, que, como seus familiares, vive em situações de extrema vulnerabilidade e enfrenta maiores obstáculos no acesso à saúde. Portanto, são necessárias abordagens interinstitucionais eficazes, de modo a oportunizar chances de prevenção e garantia efetiva do direito à saúde, sob pena de o Estado ser responsabilizado por sua omissão.

O acesso das PPL à vacinação contra o COVID-19, associado à ampliação das medidas básicas de controle de transmissão nas prisões, com teste diagnóstico e assistência em conformidade com as boas práticas clínicas, são direitos fundamentais. Para a preservação desses direitos, será necessária uma ativa fiscalização por parte dos órgãos do sistema de justiça (especialmente Ministério Público e Defensorias) e por organizações da sociedade civil, para que, em particular, a totalidade da população prisional seja efetivamente vacinada no tempo devido, em igualdade de condições com a população em geral, por uma questão de justiça.

\section{Colaboradores}

Todos os autores contribuíram na redação e revisão do manuscrito.

\section{Informações adicionais}

ORCID: Luciana Simas (0000-0003-2494-8747); Bernard Larouze (0000-0001-9906-6293); Vilma Diuana (0000-0002-7373-3446); Alexandra Sánchez (0000-0001-5617-1173).

\section{Referências}

1. Corte Interamericana de Direitos Humanos. Resolução da Corte Interamericana de Direitos Humanos, de 22 de novembro de 2018. Medidas provisórias a respeito do Brasil: assunto do Instituto Penal Plácido de Sá Carvalho. https:// www.corteidh.or.cr/docs/medidas/placido_ se_03_por.pdf (acessado em 21/Dez/2020).

2. Supremo Tribunal Federal. ADPF no 347. http:// portal.stf.jus.br/processos/downloadPeca. asp?id=308712125\&ext=.pdf (acessado em 21) Dez/2020).

3. Sánchez A, Simas L, Diuana V, Larouze B. COVID-19 nas prisões: um desafio impossível para a saúde pública? Cad Saúde Pública 2020; 36:e00083520. 
4. Conselho Nacional de Justiça. Recomendação no 62, de 17 de março de 2020. Recomenda aos Tribunais e magistrados a adoção de medidas preventivas à propagação da infecção pelo novo coronavírus - Covid-19 no âmbito dos sistemas de justiça penal e socioeducativo. https://www.cnj.jus.br/wp-content/ uploads/2020/03/62-Recomendação.pdf (acessado em 21/Dez/2020).

5. Departamento Penitenciário Nacional. Levantamento Nacional de Informações Penitenciárias. https://www.gov.br/depen/pt-br/sisde pen/sisdepen (acessado em 12/Mar/2021).

6. Departamento Penitenciário Nacional. Painel de Monitoramento dos Sistemas Prisionais medidas de combate ao COVID. https://app. powerbi.com/view? r=eyJrIjoiYThhMjk5Y jgtZWQwYS 00ODlkLTg4NDgtZTFh MTgzYmQ2MGVlIiwidCI6ImViMDkwN DIwLTQ0NGMtNDNmNy05MWYyLTRiO GRhNmJmZThlMSJ9 (acessado em 12/Mar/ 2021).

7. Conselho Nacional de Justiça. Novos óbitos por Covid-19 em unidades de privação de liberdade sobem 190\%. Agência CNJ de Notícias 2021; 11 mar. https://www.cnj.jus.br/novos-obitospor-covid-19-em-unidades-de-privacao-deliberdade-sobem-190/.

8. Siva N. Experts call to include prisons in COVID-19 vaccine plans. Lancet 2020; 396:1870.

9. Toner E, Barnill A, Krubiner C, Bernstein J, Privor-Dumm L, Watson M, et al. Interim framework for COVID-19 vaccine allocation and distribution in the United States. https://www. centerforhealthsecurity.org/our-work/pubs_ archive/pubs-pdfs/2020/200819-vaccine-allo cation.pdf (acessado em 12/Mar/2021).
10. Brasil. Plano preliminar de vacinação contra a Covid-19 do Governo Federal prevê quatro fases. https://www.gov.br/casacivil/pt-br/as suntos/noticias/2020/dezembro/plano-pre liminar-de-vacinacao-contra-a-covid-19-dogoverno-federal-preve-quatro-fases (acessado em 12/Mar/2021).

11. Ministério da Saúde. Plano Nacional de Operacionalização da Vacinação contra a Covid-19. https://www.conjur.com.br/dl/lewandowskijulgamento-compra-vacinas.pdf (acessado em 12/Mar/2021).

12. Ministério da Saúde. Plano Nacional de Operacionalização da Vacinação contra a Covid-19. https://www.gov.br/saude/pt-br/media/ pdf/2020/dezembro/16/plano_vacinacao_ver sao_eletronica.pdf (acessado em 12/Mar/2021).

13. Diogo D. Juíza pede à Saúde vacinação imediata contra covid-19 de presos do DF. Correio Braziliense 2021; 4 fev. https:// www.correiobraziliense.com.br/cidadesdf/2021/02/4904732-juiza-pede-a-saude-va cinacao-imediata-contra-covid-19-de-presosdo-df.html.

14. Job Neto F, Miranda RB, Coelho RA, Gonçalves CP, Zandonade E, Miranda AE. Health morbidity in Brazilian prisons: a time trends study from national databases. BMJ Open 2019; 9:e026853.

15. Conselho Nacional de Política Criminal e Penitenciária. Resolução no 14, de 4 de fevereiro de 2020. Priorização da vacinação dos servidores do sistema prisional e pessoas privadas de liberdade no Plano Nacional de Operacionalização da Vacina Contra a Covid-19. https://www. in.gov.br/en/web/dou/-/resolucao-n-14-de-4de-fevereiro-de-2021-302791438 (acessado em 12/Mar/2021). 